\title{
O PLANETÁRIO COMO RECURSO DIDÁTICO PARA O ENSINO DE ASTRONOMIA E DE UMA ALFABETIZAÇÃO CIENTÍFICA À LUZ DA BASE NACIONAL COMUM CURRICULAR
}

\author{
José Ademir Damasceno Júnior* \\ Mairton Cavalcante Romeu**
}

\begin{abstract}
Resumo: No Brasil, o ensino de Astronomia apresenta muitas limitações. Pesquisas apontam a má formação inicial dos professores como sendo umas das principais dificuldades. Autores indicam que o Planetário apresenta diversas vantagens para o ensino de Astronomia, tais como: despertar a motivação do aluno e facilitar a compreensão do universo. A Base Nacional Comum Curricular (BNCC), documento que norteará a educação brasileira nos próximos anos, define as aprendizagens essenciais, por exemplo, a alfabetização científica, que os alunos devem desenvolver no decorrer dos níveis e modalidades da Educação Básica. Nesse sentido, levantouse o questionamento de como o Planetário pode contribuir para o ensino de Astronomia e de uma alfabetização científica à luz da BNCC. Este trabalho teve como objetivo realizar um estudo introdutório sobre essa temática, através de um levantamento bibliográfico, no período de 1996 a 2018, tomando por base autores da área, documentos oficiais nacionais e resultados de pesquisas anteriores descritos em artigos, dissertações e teses. Neste trabalho, concluiu-se que o Planetário, quando devidamente explorado em suas potencialidades, contribui para o ensino de Astronomia e de uma alfabetização científica, possibilitando aos professores ressignificarem a sua prática pedagógica.
\end{abstract}

Palavras-chave: Ensino de Astronomia. Planetário. Recurso didático. Alfabetização científica. Base nacional comum curricular.

\section{Introdução}

Os Parâmetros Curriculares Nacionais para o Ensino Médio (PCNEM) orientam que as tecnologias, por exemplo, softwares educacionais (objetos de aprendizagem), Planetário entre outros, sejam implementadas efetivamente no processo de ensino-aprendizagem. Apesar disso, infelizmente, estas não foram exploradas significativamente no ensino de ciências (DAMASCENO, 2016).

\footnotetext{
* Mestre em Física pelo Programa de Pós-Graduação em Ensino de Ciências e Matemática (PGECM), do Instituto Federal de Educação, Ciência e Tecnologia do Ceará (IFCE). Professor da Secretaria da Educação Básica do Ceará (SEDUC).

** Doutorando em Astrofísica no Departamento de Física da Universidade Federal do Ceará (UFC). Doutor em Engenharia de Teleinformática pela Universidade Federal do Ceará (UFC). Professor do Programa de PósGraduação em Ensino de Ciências e Matemática (PGECM), do Instituto Federal de Educação, Ciência e Tecnologia do Ceará (IFCE).
}

\# Tear: Revista de Educação Ciência e Tecnologia, Canoas, v.8, n.1, 2019. 


\section{\#tear}

No Brasil, as escolas públicas ainda apresentam uma tímida utilização dos recursos tecnológicos pelos professores, seja devido a uma formação inicial inadequada ou por falta de tempo para preparar atividades diferenciadas (BRETONES, 2006; LEITE, 2006; GUIDOTTI, 2014).

A Base Nacional Comum Curricular - BNCC, documento normativo que norteará a educação brasileira nos próximos anos, define de forma orgânica e progressiva as aprendizagens essenciais que os alunos devem desenvolver no decorrer dos níveis e modalidades da Educação Básica, indicando os conhecimentos e competências que todo aluno deve se apropriar em sua escolaridade.

É bastante pertinente deixar bem claro também que, ao se referir aos conteúdos mínimos necessários, a BNCC não está orientando para que os assuntos ensinados sejam agora resumidos, nem tão pouco superficiais, que os professores não aprofundem esses conteúdos, na verdade, ela está se reportando para serem estabelecidas as aprendizagens essenciais, um dos pilares da BNCC.

As aprendizagens essenciais possibilitarão que os alunos possam avançar em cada etapa, nível e módulo de ensino da educação básica. Representam um sustentáculo para que o estudante possa prosseguir os seus estudos em cursos de graduação, entre outros, visando o pleno desenvolvimento dele enquanto pessoa, sua qualificação para o trabalho e exercício da cidadania, consoante com o que recomenda a Constituição.

É possível dimensionar também a relevância das aprendizagens essenciais para o aluno compreender os fenômenos naturais do mundo que o cerca, conhecer melhor o planeta em que vive e, quando necessário, intervir sobre o mesmo com responsabilidade, de forma sustentável, assim, garantir a sobrevivência de sua espécie e de tantas outras que coabitam conosco harmonicamente, que são fonte de alimento e responsáveis pelo equilíbrio ambiental.

O planetário, como recurso tecnológico e didático para o ensino de Astronomia, classifica-se como um ambiente não-formal de aprendizagem, pois este local proporciona situações não vividas nas escolas (FALK; STORKSDIECK, 2005). Braund e Reiss (2006) destacam a contribuição desses ambientes na elaboração de um melhor currículo de ciências, indicando que a aprendizagem nesses lugares é mais relevante. Falk e Storksdieck (2005) corroboram com esse pensamento, pois esses ambientes levam em consideração a inserção dos indivíduos no mundo virtual por meio de simulações do mundo real. 
Este trabalho consiste num levantamento bibliográfico sobre o Planetário como recurso didático para o ensino de Astronomia e de uma alfabetização científica, tomando por base os autores da área, documentos oficiais nacionais e resultados de pesquisas anteriores descritos em artigos, dissertações e teses, no período de 1996 a 2018, por meio de consultas a plataformas digitais. A qualidade das produções científicas que foram analisadas foi verificada através da pertinência dos resumos dos trabalhos em relação ao objeto de estudo desta pesquisa. Foi avaliado também o Qualis dos periódicos das revistas, nas quais estavam inseridos os artigos. Conforme Gil (2008), uma pesquisa bibliográfica é desenvolvida com base em material já elaborado, constituído principalmente de livros e artigos científicos.

\title{
2 Ensino de Astronomia e uso do Planetário como ambiente não formal
}

É possível encontrar em diversos trabalhos que a Astronomia desperta o interesse dos alunos. Ela está presente no currículo de ciências e a indicação de seu ensino também é verificada nos Parâmetros Curriculares Nacionais (PCN). Entretanto, existe uma lacuna entre os documentos oficiais e o que se verifica nas escolas. Mesmo sendo um assunto bastante verificado na mídia, existe uma discrepância em nossas salas de aulas.

A fim de embasar essa discussão, vejamos o seguinte alerta:

\begin{abstract}
Mesmo sem considerar-se que os conteúdos são o único aspecto importante, não há dúvida de que os professores de modo geral carecem de noções básicas de todo tipo de conteúdo, como por exemplo, o tratado nesta pesquisa: a Astronomia. A aprendizagem de novos conteúdos por professores está relacionada diretamente com a sua aplicação no cotidiano e também a presença de tais conteúdos nos programas de suas disciplinas e até, mais diretamente, nos livros didáticos. O domínio de conteúdos de um determinado campo deve levar mais facilmente à conquista da autonomia por parte dos professores (BRETONES, 2006, p. 10).
\end{abstract}

Nesse sentido, Negrão (1996) discorre sobre a insuficiência de conhecimentos do conteúdo pelos professores, que, desse modo, constitui-se num sério obstáculo para envolver os alunos na aula. Ele também aponta que a abordagem tradicional de ensino adotada por alguns professores pode ser devida, em grande parte, à própria carência de domínio do conteúdo (NEGRÃO, 1996).

Conforme Langhi (2009), o ensino de Astronomia nas escolas apresenta sérios problemas quando é verificado, pois em muitas escolas os professores não trabalham claramente os seus conteúdos. Para ele, isto se deve à má formação dos professores brasileiros nessa área. 
No Brasil, verifica-se em suas regiões uma inquietante desigualdade na oferta da disciplina de Astronomia pelas universidades, representando um entrave para o desenvolvimento dessa ciência no país.

\begin{abstract}
Quando analisamos a distribuição da disciplina de Astronomia pelas regiões [...] verifica-se que no Norte, nenhum curso avaliado possui disciplina obrigatória com esse conteúdo na sua estrutura curricular. Em 13 dos 15 cursos não há sequer uma disciplina optativa/eletiva. [...] No Nordeste a situação é um pouco diferente, mas não muito melhor. Nessa região há 3 cursos com disciplinas obrigatórias, mas 24 dos 37 cursos não possuem essa disciplina. Nessas duas regiões quase todos os cursos e consequentemente alunos estão em instituições públicas (ROBERTO JUNIOR; REIS; GERMINARO, 2014, p. 95).
\end{abstract}

Defende-se que uma distribuição mais equitativa pelo território brasileiro de cursos que ofereçam essa área do conhecimento, sobretudo como disciplina obrigatória, poderá contribuir de forma mais significativa para o avanço do ensino de Astronomia.

Castro, Pavani e Alves (2009) afirmam que a educação em Astronomia - apesar de encontrarmos muitos estudos e pesquisas feitas pela comunidade científica - no Brasil, infelizmente, quando direcionamos para o campo de ensino, há poucos trabalhos publicados nos periódicos brasileiros.

Santana (2017) relata que no ano de 2011, na primeira edição do "Simpósio Nacional de Educação em Astronomia" (SNEA), o evento foi dividido em 5 grandes áreas para envio de trabalhos, a saber: Ensino Formal, Ensino Não formal, Formação de Professores, Astronomia Cultural e Divulgação de Astronomia. A autora demonstrou uma preocupação com a questão dos espaços não formais (ENF):

Neste ano, foram apresentados 98 trabalhos, distribuídos em 30 comunicações orais e 68 comunicações em painéis. Dentre as apresentações, 5 orais e 11 painéis traziam a questão dos ENF. O evento ainda trouxe uma Mesa Redonda com o título "Divulgação e Espaços Não Formais", para maiores discussões sobre o tema (SANTANA, 2017, p. 18).

Santana (2017) investigou também no que concerne às pesquisas da $2^{\mathrm{a}}$ edição do SNEA, em 2012, num total de 86 trabalhos, e constatou que 3 apresentações orais e 11 apresentações em painéis abordavam a questão dos ENF no ensino de Astronomia. Neste evento, ocorreu o "Encontro de Pesquisa em Educação Não Formal” que possibilitou discussões e reflexões sobre o assunto e também a palestra "Astronomia no Planetário: mito, cultura e ciência". 
A autora percebeu ainda em sua pesquisa que os ENF são pouco utilizados. Para ela, normalmente, este fato se dá devido à falta de conhecimento metodológico e teórico sobre esses por parte dos professores. Contudo, ela indica que, infelizmente, estes mesmos trabalhos pouco discutem sobre quais seriam as teorias e metodologias necessárias para ajudar o professor durante sua visitação.

O ambiente de ensino pode favorecer ou não a aprendizagem. Nesse sentido, segundo Romanzini e Batista (2009), encontramos na literatura três tipos de ambientes, que se classificam de acordo com seus objetivos educacionais. Os ambientes formais são caracterizados por sua estrutura física (por exemplo, salas de aula, bibliotecas, refeitório e quadras esportivas), e por uma equipe pedagógica especializada (professores, diretores, coordenadores, dentre outros). Escolas e Universidades são exemplos de ambientes formais.

No tocante aos espaços não formais, Romanzini e Batista (2009) indicam que são aqueles que se encontram fora do ambiente formal de ensino e que possibilitam situações diferenciadas para a aprendizagem. Neles encontramos uma estrutura técnico-científica. São exemplos destes ambientes: Museus, Centros de Ciências, Planetários, Zoológicos, Observatórios, entre outros.

O fato de os ambientes não formais possibilitarem atividades práticas e observacionais, que despertam a curiosidade dos alunos e que atendem aos seus interesses, pouco verificado num ambiente escolar, tornam a aprendizagem mais significativa (SIMSON et al., 2001).

\section{O ensino de Ciências e o recurso Planetário em consonância com a Base Nacional Comum Curricular - BNCC}

Na BNCC, a área de Ciências da Natureza tem a incumbência da alfabetização científica, que possibilitará que o indivíduo tenha não somente a capacidade de compreender e interpretar o mundo natural, social e tecnológico, mas também para saber agir sobre ele, modificá-lo, embasado nos aportes teóricos e sistemáticos da ciência. Portanto, aprender por meio da alfabetização científica é muito mais do que compreender os fenômenos naturais, mas a construção da capacidade de ação sobre o mundo, exercendo assim sua cidadania, consciente de suas responsabilidades.

A fim de que os estudantes atinjam esse nível de alfabetização científica, com consciência crítica e responsável, a BNCC defende que: 
Para tanto, é imprescindível que eles sejam progressivamente estimulados e apoiados no planejamento e na realização cooperativa de atividades investigativas, bem como no compartilhamento dos resultados dessas investigações. Isso não significa realizar atividades seguindo, necessariamente, um conjunto de etapas pré-definidas, tampouco se restringir à mera manipulação de objetos ou realização de experimentos em laboratório (BRASIL, 2017, p. 274).

Segundo Chassot (2003, p. 93), “Quando nos referimos ao entendimento do mundo natural, há uma restrição epistemológica e ficamos limitados ao entendimento deste nosso mundo visível onde estamos inseridos, logo, do qual somos parte".

Damasceno Júnior e Romeu (2018, p. 234) esclarecem que “[...] os obstáculos epistemológicos constituem-se como fatores de resistência, conservação do pensamento, uma preferência pelas respostas prontas e não por questioná-las". Os autores afirmam ainda que "Na obra de Bachelard podemos encontrar uma forte crítica que o mesmo faz acerca da concepção ocularista de conhecimento, que considera a visão como o sentido essencial do saber" (DAMASCENO JÚNIOR; ROMEU, 2018, p. 234).

Remetendo-se novamente a Chassot (2003, p. 93), este elucida que:

A elaboração dessa explicação do mundo natural - diria que isso é fazer ciência, como elaboração de um conjunto de conhecimentos metodicamente adquirido - é descrever a natureza numa linguagem dita científica. Propiciar o entendimento ou a leitura dessa linguagem é fazer alfabetização científica (CHASSOT, 2003, p. 93).

Auler e Delizoicov (2001, p. 1) contribuem também com a discussão ao declararem que:

Contudo, o rótulo Alfabetização Científica e Tecnológica abarca um espectro bastante amplo de significados traduzidos através de expressões como popularização da ciência, divulgação científica, entendimento público da ciência e democratização da ciência. Os objetivos balizadores são diversos e difusos. Vão desde a busca de uma autêntica participação da sociedade em problemáticas vinculadas à CT, até aqueles que colocam a ACT na perspectiva de referendar e buscar o apoio da sociedade para a atual dinâmica do desenvolvimento científico-tecnológico. Em outros termos, há, por um lado, encaminhamentos mais próximos de uma perspectiva democrática e, por outro, encaminhamentos que direta ou indiretamente respaldam postulações tecnocráticas (AULER; DELIZOICOV, 2001, p. 2).

Nesse sentido, entende-se que a alfabetização científica não pode estar respaldada numa visão conformista que a sociedade deve seguir e obedecer única e exclusivamente aos "dogmas" da ciência, ou seja, às suas leis, teorias e descobertas, até porque em ciências não existem verdades absolutas. 
É possível destacar dois pontos para uma discussão. O primeiro refere-se ao fato da produção científica e suas aplicações serem um constructo do conhecimento humano, devendose, portanto, serem concebidas por meio de uma participação crítica, efetiva e democrática de todos os segmentos da sociedade. A tomada de decisão não deve ser realizada apenas por cientistas, ou somente por setores específicos, que tenham investido nas pesquisas, visando benefícios próprios, por exemplo, lucros financeiros.

Em linhas gerais, a alfabetização científica deve proporcionar aos alunos não somente o conhecimento acerca da natureza, mas possibilitar que o indivíduo possa compreender todos os mecanismos físicos, químicos, biológicos, sociais, econômicos, entre outros, implícitos nos processos, para uma tomada de decisão lúcida e responsável, que não venha a comprometer a interação e a sobrevivência das espécies no mundo em que vivemos.

Ainda sobre a relevância da pesquisa na alfabetização científica dos estudantes, a BNCC afirma que "o processo investigativo deve ser entendido como elemento central na formação dos estudantes, em um sentido mais amplo, e cujo desenvolvimento deve ser atrelado a situações didáticas planejadas ao longo de toda a educação básica [...]” (BRASIL, 2017, p. 274).

Nesse contexto, a área de Ciências da Natureza, com a contribuição de outras áreas e campos do saber, deverá garantir aos alunos o acesso ao conhecimento científico construído no decorrer da história e, ao mesmo, tempo possibilitar a apropriação dos processos e técnicas pertinentes a uma investigação científica, em consonância com o nível cognitivo e a etapa de escolarização desses estudantes.

Nesse viés, a área de Ciências da Natureza deve oportunizar aos alunos no ensino Fundamental o desenvolvimento de competências específicas. Sobre a necessidade de compreender a importância das ciências, assim como de seus conceitos, a BNCC, nas Competências 1 e 2, explicita que os alunos devem:

1. Compreender as ciências como empreendimento humano, reconhecendo que o conhecimento científico é provisório, cultural e histórico.[...] 2. Compreender conceitos fundamentais e estruturas explicativas das Ciências da Natureza, bem como dominar processos, práticas e procedimentos da investigação científica, de modo a sentir segurança no debate de questões científicas, tecnológicas e socioambientais e do mundo do trabalho (BRASIL, 2017, p. 276).

Percebe-se, novamente, a relevância da investigação científica à luz da BNCC no processo de formação dos alunos, possibilitando que estes se apropriem de informações de fontes 
confiáveis e que possam utilizar como argumentos ao participarem de debates na escola e em outros espaços e contextos na sociedade, sejam essas informações de natureza científica, tecnológica, socioambiental, dentre outras.

Para os estudantes desenvolverem o nível de análise e avaliação dos fenômenos e processos relativos ao mundo em que vivem, assim como de suas implicações, a BNCC, nas Competências 3 e 4, orienta que eles devem ter a capacidade de:

3. Analisar, compreender e explicar características, fenômenos e processos relativos ao mundo natural, tecnológico e social, como também às relações que se estabelecem entre eles, exercitando a curiosidade para fazer perguntas e buscar respostas. [...] 4. Avaliar aplicações e implicações políticas, socioambientais e culturais da ciência e da tecnologia e propor alternativas aos desafios do mundo contemporâneo, incluindo aqueles relativos ao mundo do trabalho (BRASIL, 2017, p. 276).

Diante disso, os professores devem empreender situações na escola, assim como em outros espaços e momentos de aprendizagem, que levem os alunos a refletirem sobre as relações que são estabelecidas entre ciência, tecnologia e sociedade, ao mesmo tempo sobre as consequências provenientes dessas relações. Após esse processo, o estudante deverá estar preparado para responder a alguns questionamentos, por exemplo, quais as implicações das descobertas e avanços da ciência e tecnologia na sociedade?

Sobre despertar nos indivíduos uma consciência ética e moral, de valorização da vida, de cuidado com o mundo em que habita, de respeito às diferenças, sejam elas com relação à etnia, raça, convicção religiosa, orientação sexual, política, dentre outras, a BNCC, nas Competências 5 e 6, aponta que os alunos precisam aprender a:

5. Construir argumentos com base em dados, evidências e informações confiáveis e negociar e defender ideias e pontos de vista que respeitem e promovam a consciência socioambiental e o respeito a si próprio e ao outro, acolhendo e valorizando a diversidade de indivíduos e de grupos sociais, sem preconceitos de qualquer natureza. [...] 6. Conhecer, apreciar e cuidar de si, do seu corpo e bem-estar, recorrendo aos conhecimentos das Ciências da Natureza (BRASIL, 2017, p. 276).

É fato que dificilmente um indivíduo poderá elaborar argumentos convincentes, plausíveis, sem dados de fontes confiáveis. Ele nem mesmo saberá encontrar essas informações, caso não tenha vivenciado a prática da pesquisa, da investigação científica, em sua educação básica. Também é verdade que para ele cuidar melhor de si, do seu corpo e do mundo em que 


\section{\#tear}

vive, o aluno precisará conhecer melhor o seu organismo, de como evitar e combater doenças, e sobre técnicas autossustentáveis.

Ainda na educação básica, os alunos precisam compreender que suas posturas, atitudes e decisões terão consequências coletivas em sua escola, bairro, cidade, ou seja, em seu planeta, até mesmo no universo. Eles devem entender que não vivemos de forma isolada, que existem outros inúmeros seres vivos na Terra, e que essa convivência deve ser a mais harmoniosa possível, caso contrário, poderá haver um desequilíbrio, seja de ordem social e/ou ambiental, entre outros.

Com esse pensamento, a BNCC, na Competência 7, esclarece que o aluno deve:

7. Agir pessoal e coletivamente com respeito, autonomia, responsabilidade, flexibilidade, resiliência e determinação, recorrendo aos conhecimentos das Ciências da Natureza para tomar decisões frente a questões científico-tecnológicas e socioambientais e a respeito da saúde individual e coletiva, com base em princípios éticos, democráticos, sustentáveis e solidários (BRASIL, 2017, p. 276).

Dessa forma, é vista a necessidade de serem formados, a partir da educação básica, indivíduos que saibam viver em comunidade. Estes precisam apresentar uma preocupação sempre de ordem coletiva, conscientes que suas atitudes e tomadas de decisões deverão ser responsáveis, pois poderão ter implicações, por exemplo, socioambientais. O aluno deverá ser preparado para buscar alternativas que possibilitem avanços tecnológicos sem graves consequências a outros indivíduos e ao meio ambiente.

Os alunos, no ensino Fundamental, ao estudaram o componente curricular de Ciências, aprenderão mais sobre eles próprios, acerca de outras espécies, quanto à manutenção da vida. Conhecer também sobre o nosso planeta, o Sistema Solar e o Universo possibilitará que os mesmos tenham melhor propriedade para argumentar, defender e promover intervenções com o intuito de manter o equilíbrio na natureza.

A BNCC propõe para a elaboração dos Currículos de Ciências três unidades temáticas, que devem ser estudadas e revisitadas no decorrer de todo o ensino Fundamental. A partir das unidades temáticas, os professores deverão desenvolver nos alunos as habilidades essenciais descritas no mesmo documento. As unidades temáticas são: Matéria e energia; Vida e evolução; e Terra e Universo.

Com relação à temática "Terra e Universo", sua proposta é para que os alunos estudem sobre as características da Terra, do Sol, da Lua, assim como de outros corpos celestes. Eles 
devem compreender as dimensões, composição, localização, movimentos e interação desses astros que se encontram no espaço sideral, ou seja, sobre as forças exercidas entre os mesmos.

Para tanto, além de estudos e discussões em sala de aula, são necessárias observações do céu. Os professores devem possibilitar que os alunos vivenciem cada vez mais essa experiência. Eles devem fazer suas observações para verificarem sobre as características dos corpos celestes, citadas anteriormente, ao mesmo tempo confrontarem suas primeiras concepções, de senso comum, com informações e dados embasados em fontes confiáveis, portanto, com o conhecimento científico.

É de fundamental importância que os estudantes compreendam a construção histórica de conceitos astronômicos, dos conhecimentos sobre a Terra, o céu, estrelas, planetas e de outros corpos celestes, no decorrer da história da humanidade, em diferentes culturas e contextos sociais e políticos. Eles devem ter consciência da influência das crenças religiosas sobre a origem, constituição e organização do universo, entre outros.

Sobre essa discussão, a BNCC acrescenta ainda que:

[...] a intenção é aguçar ainda mais a curiosidade das crianças pelos fenômenos naturais e desenvolver o pensamento espacial a partir das experiências cotidianas de observação do céu e dos fenômenos a elas relacionados. A sistematização dessas observações e o uso adequado dos sistemas de referência permitem a identificação de fenômenos e regularidades que deram à humanidade, em diferentes culturas, maior autonomia na regulação da agricultura, na conquista de novos espaços, na construção de calendários etc (BRASIL, 2017, p. 280).

Nesse sentido, verifica-se a relevância do estudo da Astronomia para a humanidade, pois suas observações, registros e descobertas tiveram importantes implicações, especialmente, na agricultura. Dessa forma, o Planetário apresenta-se como um relevante recurso didático, pois possibilita uma melhor visão espacial, por ser um meio de imersão, proporcionando ao indivíduo observações de fenômenos naturais, em espaços e tempos distintos, numa única sessão de poucos minutos, que dificilmente seriam vistos através de observações diretas do céu, em função da distância, da poluição visual, de fatores climáticos, entre outros.

Já nos anos finais do ensino Fundamental, essa temática dá maior ênfase ao estudo do solo, dos ciclos biogeoquímicos, do clima e de seus efeitos sobre a vida na Terra. A partir disso, de uma visão mais ampla, os alunos conseguirão desenvolver práticas ambientalmente sustentáveis, e, assim, contribuir para a sobrevivência dos seres vivos em nosso planeta. 
A BNCC aponta a necessidade de colocar em pauta, como objeto de conhecimento e habilidades a serem adquiridas, a discussão sobre modelos planetários. Os alunos devem entender por meio de estratégias diversas, por exemplo, através de simulações e construção de modelos explicativos, como o nosso sistema solar foi representado, no decorrer da história, quanto à sua organização por alguns estudiosos.

Acerca disso, a BNCC esclarece que, desse modo, “[...] privilegia-se, com base em modelos, a explicação de vários fenômenos envolvendo os astros Terra, Lua e Sol, de modo a fundamentar a compreensão da controvérsia histórica entre as visões geocêntrica e heliocêntrica" (BRASIL, 2017, p. 280-281).

Nesse contexto, por meio de uma compreensão ampliada da origem, composição, organização e evolução do Universo, os estudantes irão refletir sobre o papel da humanidade na conservação do nosso planeta, que decisões equivocadas poderão colocar em risco a manutenção da vida na Terra.

Vale ressaltar que, já no $1^{\circ}$ ano do Ensino Fundamental (EF), através da unidade temática "Terra e Universo", como objeto de conhecimento, estudam-se "escalas de tempo". As habilidades correspondentes a serem desenvolvidas nos alunos são:

Identificar e nomear diferentes escalas de tempo: os períodos diários (manhã, tarde e noite) e a sucessão dos dias, semanas, meses e anos. [...] Selecionar exemplos de como a sucessão de dias e noites orienta o ritmo de atividades diárias de seres humanos e de outros seres vivos (BRASIL, 2017, p. 285).

Verifica-se, portanto, a preocupação da BNCC para que as crianças, desde cedo, por volta dos 7 anos de idade, compreendam os períodos e sucessão dos dias e de como estes influenciam em nossas rotinas diárias e de outros seres vivos.

No $2^{\circ}$ ano do EF, ainda sobre a mesma temática, verificam-se como objetos de conhecimento "Movimento do Sol no Céu" e "O Sol como fonte de luz e calor". As habilidades que contemplam esses tópicos são:

Descrever as posições do Sol em diversos horários do dia e associá-las ao tamanho de sua própria sombra e da sombra de diferentes objetos.[...] Comparar e registrar o efeito da radiação solar (aquecimento) em diferentes tipos de superfície (água, areia, solo, superfície escura, superfície clara etc.) (BRASIL, 2017, p. 287).

Percebe-se com essas habilidades a necessidade de que os alunos entendam sobre o movimento aparente do Sol, com as possíveis posições ocupadas pelo mesmo no decorrer do dia, 
associando ao tamanho de sua própria sombra e de outros objetos. Ao mesmo tempo que os alunos deverão também identificar os efeitos da radiação solar na superfície da Terra.

Já no $3^{\circ}$ ano, a BNCC apresenta como objetos de conhecimento: "Características da Terra", "Observação do céu" e "Usos do solo". As habilidades a serem adquiridas pelos alunos serão:

Identificar características da Terra (como seu formato esférico, a presença de água, solo etc.), com base na observação, manipulação e comparação de diferentes formas de representação do planeta (mapas, globos, fotografias etc.). [...] Observar, identificar e registrar os períodos diários (dia e/ou noite) em que o Sol, demais estrelas, Lua e planetas estão visíveis no céu. [...] Comparar diferentes amostras de solo do entorno da escola com base em algumas características (cor, textura, cheiro, tamanho das partículas, permeabilidade etc.). [...] Identificar os diferentes usos do solo (plantação e extração de materiais, dentre outras possibilidades), reconhecendo a importância do solo para a vida (BRASIL, 2017, p. 289).

Nota-se nessas habilidades que a BNCC sugere que os alunos aprendam por meio de uma investigação, através do método científico. Com sucessivas observações, manipulações e comparações, os estudantes conseguirão identificar características relevantes da Terra (seu formato, presença de água, entre outros), concomitantemente, deverão realizar registros de tudo que foi observado e utilizar diferentes fontes de pesquisa, por exemplo, mapas, globos, dentre outros, a fim de fundamentar suas descobertas.

Infere-se também que a BNCC orienta que os professores devem incentivar aos alunos a realizarem observações do céu, fazendo anotações do comportamento, formas, organizações e posições do Sol, da Lua e das estrelas visíveis no decorrer do dia e da noite. É importante também que eles estudem o tipo de solo da escola, assim como de seu entorno, quanto às suas características, principalmente físicas, e, a partir disso, compreender a sua utilização, por exemplo, na agricultura.

Encontram-se no $4^{\circ}$ ano os objetos de conhecimento "Pontos cardeais" e "Calendários, fenômenos cíclicos e cultura". Para eles, a BNCC recomenda as seguintes habilidades:

Identificar os pontos cardeais, com base no registro de diferentes posições relativas do Sol e da sombra de uma vara (gnômon). [...] Comparar e explicar as diferenças encontradas na indicação dos pontos cardeais resultante da observação das sombras de uma vara (gnômon) e por meio de uma bússola. [...] Associar os movimentos cíclicos da Lua e da Terra a períodos de tempo regulares e ao uso desse conhecimento para a construção de calendários em diferentes culturas (BRASIL, 2017, p. 291). 
No $5^{\circ}$ ano, os objetos de conhecimentos propostos são: "Constelações e mapas celestes", "Movimento de rotação da Terra", "Periodicidade das fases da Lua" e "Instrumentos óticos". As habilidades estabelecidas pela a BNCC são as seguintes:

Identificar algumas constelações no céu, com o apoio de recursos, como mapas celestes e aplicativos, entre outros, e os períodos do ano em que elas são visíveis no início da noite. [...] Associar o movimento diário do Sol e demais estrelas no céu ao movimento de rotação da Terra. [...] Concluir sobre a periodicidade das fases da Lua, com base na observação e no registro das formas aparentes da Lua no céu ao longo de, pelo menos, dois meses. [...] Projetar e construir dispositivos para observação à distância (luneta, periscópio etc.), para observação ampliada de objetos (lupas, microscópios) ou para registro de imagens (máquinas fotográficas) e discutir usos sociais desses dispositivos (BRASIL, 2017, p. 293).

Nessa etapa escolar, os alunos estudarão mais detalhadamente sobre as estrelas e constelações fazendo o uso de diferentes recursos, como mapas celestes e simuladores, aplicativos, dentre outros. Eles devem também promover a associação do movimento do Sol e demais estrelas do céu, ao longo do dia, com o movimento de rotação da Terra. É interessante que os alunos entendam sobre as fases da Lua, a partir de observações do céu, pelo menos num período de dois meses.

Ressalta-se, portanto, que ao se estudar as fases da Lua, cujo ciclo leva cerca de 29 dias para se completar, através do Planetário é possível simular esse ciclo em somente uma sessão em poucos minutos de duração, evitando, assim, ter que se fazer uma série de observações diretas da Lua por um tempo muito maior, por todo o seu período.

A BNCC sugere que os professores estimulem que os alunos construam dispositivos para a observação das estrelas, da Lua e de outros planetas no céu noturno. Por meio do uso, por exemplo, de lunetas, os estudantes farão melhores observações de alguns corpos celestes.

$\mathrm{Na}$ etapa escolar do $6^{\circ}$ ano, a BNCC indica o objeto de conhecimento "Forma, estrutura e movimentos da Terra”. As habilidades recomendadas são:

Identificar as diferentes camadas que estruturam o planeta Terra (da estrutura interna à atmosfera) e suas principais características. [...] Identificar diferentes tipos de rocha, relacionando a formação de fósseis a rochas sedimentares em diferentes períodos geológicos. [...] Selecionar argumentos e evidências que demonstrem a esfericidade da Terra. [...] Inferir que as mudanças na sombra de uma vara (gnômon) ao longo do dia em diferentes períodos do ano são uma evidência dos movimentos de rotação e translação do planeta Terra e da inclinação de seu eixo de rotação em relação ao plano de sua órbita em torno do Sol (BRASIL, 2017, p. 297). 
A BNCC sugere, para o $7^{\circ}$ ano do ensino Fundamental, como objetos de conhecimento: "Composição do ar", "Efeito estufa", "Camada de ozônio", "Fenômenos naturais (vulcões, terremotos e tsunamis)" e "Placas tectônicas e deriva continental".

A BNCC estabelece, para essa etapa escolar, as seguintes habilidades:

Demonstrar que o ar é uma mistura de gases, identificando sua composição, e discutir fenômenos naturais ou antrópicos que podem alterar essa composição. [...] Descrever o mecanismo natural do efeito estufa, seu papel fundamental para o desenvolvimento da vida na Terra, discutir as ações humanas responsáveis pelo seu aumento artificial (queima dos combustíveis fósseis, desmatamento, queimadas etc.) e selecionar propostas para a reversão ou controle desse quadro. [...] Justificar a importância da camada de ozônio para a vida na Terra identificando os fatores que aumentam ou diminuem sua presença na atmosfera. [...] Interpretar fenômenos naturais (como vulcões, terremotos e tsunamis) e justificar a rara ocorrência desses fenômenos no Brasil, com base no modelo das placas tectônicas. [...] Justificar o formato das costas brasileira e africana com base na teoria da deriva dos continentes (BRASIL, 2017, p. 299).

Desse modo, os estudantes poderão sensibilizar, informar e promover mudanças no comportamento da comunidade escolar e local, através, por exemplo, de campanhas para combater as queimadas, o desmatamento e reduzir a emissão de gases provenientes da queima de combustíveis fósseis para o meio ambiente, prejudicando assim a camada de ozônio e causando um desequilíbrio no efeito estufa. Portanto, os alunos contribuirão para a adoção e ampliação de práticas sustentáveis.

No que se refere ao $8^{\circ}$ ano, temos como objetos de conhecimento: "Sistema Sol, Terra e Lua" e "Clima". As habilidades correspondentes são:

Justificar, por meio da construção de modelos e da observação da Lua no céu, a ocorrência das fases da Lua e dos eclipses, com base nas posições relativas entre Sol, Terra e Lua. [...] Representar os movimentos de rotação e translação da Terra e analisar o papel da inclinação do eixo de rotação da Terra em relação à sua órbita na ocorrência das estações do ano, com a utilização de modelos tridimensionais. [...] Relacionar climas regionais aos padrões de circulação atmosférica e oceânica e ao aquecimento desigual causado pela forma e pelos movimentos da Terra. [...] Identificar as principais variáveis envolvidas na previsão do tempo e como elas são medidas. [...] Discutir iniciativas que contribuam para restabelecer o equilíbrio ambiental a partir da identificação de alterações climáticas regionais e globais provocadas pela intervenção humana (BRASIL, 2017, p. 301).

Percebe-se que algumas habilidades são recorrentes ao longo de todo o ensino Fundamental, por exemplo, no que diz respeito à construção de modelos e da observação das fases da Lua, da compreensão dos movimentos de rotação e translação da Terra, assim como do 
papel da inclinação do seu eixo de rotação em relação ao plano de sua órbita. Acreditamos que essa recorrência se deve ao fato de sua relevância, pois esses fenômenos inquietantes são observados e estudados há muitos séculos.

Às fases da Lua, aos fenômenos dos eclipses e aos movimentos dos planetas, no decorrer da história da humanidade, foram dadas diversas explicações, atribuídos diferentes significados, principalmente, com uma conotação religiosa, através da influência de crenças e mitos. Nesse sentido, faz-se necessário que os alunos, agora na adolescência, compreendam a evolução dos conceitos desses fenômenos construídos historicamente.

Os estudantes compreenderão que muitos fenômenos naturais foram explicados por meio do senso comum, uma visão superficial e ingênua do mundo real. Assim, deverão concluir que o olhar crítico perpassa pelo conhecimento científico, que se baseia num estudo minucioso, investigativo e que parte de um fenômeno ou problema a ser explicado.

Por fim, no tocante ao $9^{\circ}$ ano, encontram-se um número maior de objetos de conhecimento, de estudo um pouco mais complexo e aprofundado. São eles: "Composição, estrutura e localização do Sistema Solar no Universo", "Astronomia e cultura", "Vida humana fora da Terra", "Ordem de grandeza astronômica" e "Evolução estelar".

Para contemplar esses objetos de conhecimento, temos as habilidades a seguir:

\begin{abstract}
Descrever a composição e a estrutura do Sistema Solar (Sol, planetas rochosos, planetas gigantes gasosos e corpos menores), assim como a localização do Sistema Solar na nossa Galáxia (a Via Láctea) e dela no Universo (apenas uma galáxia dentre bilhões). [...] Relacionar diferentes leituras do céu e explicações sobre a origem da Terra, do Sol ou do Sistema Solar às necessidades de distintas culturas (agricultura, caça, mito, orientação espacial e temporal etc.). [...] Selecionar argumentos sobre a viabilidade da sobrevivência humana fora da Terra, com base nas condições necessárias à vida, nas características dos planetas e na ordem de grandeza das medidas astronômicas. [...] Analisar o ciclo evolutivo do Sol (nascimento, vida e morte) baseado no conhecimento das etapas de evolução de estrelas de diferentes dimensões e os efeitos desse processo no nosso planeta (BRASIL, 2017, p. 303).
\end{abstract}

Os alunos agora terão que estudar sobre a composição e estrutura do Sistema Solar. Eles terão que pesquisar sobre a origem da Terra, do Sol ou do Sistema Solar. Identificar as condições necessárias à vida, na Terra ou até mesmo fora dela. Saber também sobre as ordens de grandeza astronômica, de sua utilização e relevância. Os estudantes compreenderão sobre as etapas da evolução estelar, suas consequências no universo e também em nosso planeta. 


\section{\#tear}

Novamente, ressalta-se neste trabalho a relevância do Planetário como recurso didático para o ensino de Astronomia, pois de que forma se pode estudar a composição e a estrutura do Sistema Solar em nossa galáxia e dela no Universo? Como apresentar modelos sobre a origem da Terra, do Sol ou do Sistema Solar? De que meio verificar as características dos planetas e na ordem de grandeza das medidas astronômicas? Qual a maneira de se analisar o ciclo evolutivo do Sol baseado nas etapas de evolução das estrelas? Como observar tudo isso, em diferentes espaços e tempos, de forma interativa, considerando que a expectativa de vida da espécie humana é insignificante quando comparada aos fenômenos astronômicos citados anteriormente?

Numa única sessão do Planetário, de poucos minutos, é possível realizar uma impressionante "viagem" espacial. Percorrer espaços longínquos pela imensidão do Universo. Verificar características físicas e químicas de inúmeros corpos celestes. Observar o ciclo de uma

estrela, através de bilhões de anos. Impensável? Não. É possível por meio de um valioso recurso didático, um fabuloso meio de imersão e interação, denominado Planetário.

Verifica-se nessas habilidades a possibilidade de explorar inúmeros conceitos astronômicos. Colocar à prova conceitos de senso comum, por meio de pesquisas, construção de modelos, utilização de simuladores, visitas a centros de pesquisa, a Planetários e discussões mediadas pelo professor.

É importante destacar que neste trabalho utilizou-se a BNCC referente ao ensino Fundamental, pois ainda não havia sido aprovado o mesmo documento para o ensino Médio. Apesar disso, acredita-se que não comprometeu esta pesquisa, devido ao fato de muitos conceitos astronômicos estudados no ensino Fundamental serem recorrentes até mesmo no ensino Médio. Esses assuntos são revisitados constantemente.

\section{Considerações finais}

A partir de um estudo introdutório, através de uma revisão bibliográfica, foi possível tomar algumas inferências sobre o ensino de Astronomia no Brasil. Apesar de alguns esforços, por meio da legislação vigente e de alguns trabalhos científicos, o mesmo é ainda bem superficial e apresenta diversas dificuldades, como, por exemplo, uma má formação inicial dos professores nessa área do conhecimento, um número insignificante e uma distribuição desigual de cursos de graduação em Astronomia no território brasileiro, dentre outras. 
Foi possível constatar também que muitos autores indicam o uso do Planetário como um recurso didático, um ambiente não-formal, para o ensino de Astronomia, por apresentar inúmeras vantagens, tais como: despertar a motivação do aluno, sua curiosidade; facilitar a compreensão do universo e dos corpos celestes, sua organização e composição, entre outros. Acredita-se que o Planetário se apresenta como um recurso motivacional, que provoca inquietações nos alunos, pelo fato de ser um local com características bem diferentes do que geralmente os estudantes encontram nas escolas.

As sessões de cúpula possibilitam que os alunos tenham uma visão dinâmica do Universo, normalmente contrário ao que eles observam em sala de aula, basicamente através dos livros didáticos e/ou modelos esquemáticos representados pelos professores. Os objetos astronômicos apresentados nos livros didáticos, ou esquematizados no quadro da sala de aula pelo professor, limitam-se a uma figura estática num plano bidimensional. Realidade bem diferente do que o estudante verificará no ambiente Planetário, onde os distintos objetos celestes são projetados em movimento, num espaço tridimensional (meio de imersão).

O fato do Planetário ser um recurso que projeta os objetos celestes em movimento, possibilita ao aluno abstrair mais facilmente, por exemplo, o movimento de precessão da Terra (fenômeno físico que consiste na mudança do seu eixo de rotação). Todavia, procurar observar este movimento, dentre outros no Universo, através de uma imagem estática e bidimensional, contidas nos livros didáticos, entre outros semelhantes materiais de apoio, torna-se uma tarefa bem mais árdua e complicada para os estudantes. Nesse contexto, acredita-se que a observação dos movimentos e interações (força gravitacional, por exemplo) que ocorrem no espaço sideral, por meio do Planetário, facilitará a compreensão desses fenômenos naturais, de leis e teorias científicas, assim, este recurso didático contribuirá de forma significativa para a alfabetização científica.

Neste trabalho, conclui-se que o uso do Planetário, enquanto recurso didático, desenvolverá nos estudantes as aprendizagens essenciais previstas na BNCC, como, por exemplo, uma alfabetização científica, em que os mesmos poderão compreender melhor o mundo natural, por meio de leis e teorias discutidas a nível científico. Concomitantemente, os alunos deverão entender também as transformações que os avanços científicos e tecnológicos poderão causar na sociedade. A partir dessa compreensão, tomar decisões com consciência e responsabilidade, vislumbrando o bem-estar de todas as pessoas. 
THE PLANETARY AS A DIDACTIC RESOURCE FOR THE ASTRONOMY TEACHING AND A SCIENTIFIC LITERACY IN THE LIGHT OF THE COMMON CURRICULAR NATIONAL

\title{
BASIS
}

\begin{abstract}
In Brazil, the Astronomy teaching has many limitations. Research points to the initial poor teacher training as one of the main difficulties. Authors indicate that the Planetarium presents several advantages for the Astronomy teaching, such as: awakening the student's motivation and facilitating the understanding of the universe. The National Curricular National Base (BNCC), a document that will guide Brazilian education in the coming years, defines the essential learning, for example, scientific literacy, which students must develop throughout the levels and modalities of Basic Education. In this way, the question has arisen of how the Planetarium can contribute to the Astronomy teaching and for a scientific literacy in the light of the BNCC. This work had the objective to carry out an introductory study on this theme, through a bibliographical survey, from 1996 to 2018, based on authors of the area, national official documents and results of previous researches described in articles, dissertations and theses. In this work, it was concluded that the Planetarium, when properly exploited in its potential, contributes to the Astronomy teaching and a scientific literacy, enabling teachers to re-signify their pedagogical practice.
\end{abstract}

Keywords: Astronomy Teaching. Planetary. Didactic resource. Scientific literacy. Common national curriculum base.

\section{Referências}

AULER, D.; DELIZOICOV, D. Alfabetização científico-tecnológica para quê? Ensaio: pesquisa em educação em ciências, v. 3, n. 1, p. 105-115, 2001.

BRASIL, Ministério da Educação. Secretaria de Ensino Básico. Parâmetros Curriculares Nacionais Ensino Médio. Brasília: MEC/SEB, 2000. 109 p.

BRASIL, Ministério da Educação, Secretaria de Educação Básica. PCN+: Ensino Médio orientações educacionais complementares aos parâmetros curriculares nacionais. Brasília: MEC/SEB, 2002.

BRASIL. Ministério da Educação. Governo Federal. Base Nacional Curricular Comum. 2017. Disponível em: <http://basenacionalcomum.mec.gov.br/wp-content/uploads/2018/02/bncc20dez-site.pdf>. Acesso em: 28 fev. 2018.

BRASIL. Secretaria de Educação Média e Tecnologia. Parâmetros Curriculares Nacionais: ciências naturais. Brasília: MEC/SEMTEC, 1998. 
BRAUND, M.; REISS, M. Towards a more authentic science curriculum: the contribution of out-of-school learning. International Journal of Science Education, v.28, n.12, p.1373-1388, out.2006.

BRETONES, P. S. A Astronomia na formação continuada de professores e o papel da racionalidade prática para o tema da observação do céu. Tese de doutorado. Programa de Pós Graduação em Ensino e História de Ciências da Terra. Universidade Estadual de Campinas. 252 p. 2006.

CASTRO, E. S. B.; PAVANI, D. B.; ALVES, V. M. A Produção Em Ensino De Astronomia Nos Últimos Quinze Anos. In: XVIII Simpósio Nacional de Ensino de Física. Vitória - ES, 2009.

CHASSOT, A. I. Alfabetização científica: uma possibilidade para a inclusão social. Revista Brasileira de Educação, São Paulo, v. 23, n. 22, p. 89-100, 2003.

DAMASCENO, J. C. G. $O$ ensino de astronomia como facilitador nos processos de ensino e aprendizado. Dissertação de Mestrado. Programa de Pós-Graduação Mestrado Nacional Profissional de Ensino de Física (MNPEF). Universidade Federal do Rio Grande, Rio Grande, 137 pp. 2016.

DAMASCENO JÚNIOR, J. A; ROMEU, M. C. O Planetário como recurso metodológico para facilitar o ensino de Física por meio da ruptura entre o conhecimento científico e o conhecimento comum. Revista Prática Docente, Confresa, v. 3, n. 1, p. 231-248, 2018.

FALK, J., STORKSDIECK, M. Using the Contextual Model of Learning to Understand Visitor Learning from a Science Center Exhibition. Wiley Periodicals, Inc. Sci ed 89, 744- 778, 2005.

GIL, A. C. Como elaborar projetos de pesquisa. 4 ed. São Paulo: Atlas, 2008.

GUIDOTTI, C. S. Investigando a inserção das tecnologias na formação inicial dos professores de física nas universidades federais do Rio Grande do Sul. Dissertação de Mestrado. Programa de Pós Graduação em Educação em Ciências. Universidade Federal do Rio Grande. 119 p. 2014.

LANGHI, R. Astronomia nos iniciais do ensino fundamental: repensando a formação de professores. Tese de Doutorado. Programa de Pós Graduação em Educação para Ciência. Faculdade de Ciências, Universidade Estadual de São Paulo, Bauru, 370 pp. 2009.

LEITE, C. Formação do professor de ciências em astronomia: uma proposta com enfoque na espacialidade. Tese de Doutorado. Programa de Pós-Graduação em Educação. Faculdade de Educação, Universidade de São Paulo, São Paulo, 274 pp. 2006.

NEGRÃO, O. B. M. Especialização em geociências: análise de uma prática. Campinas: FE/UNICAMP, 1996, 232p. 
ROBERTO JUNIOR, A. J.; REIS, T. H.; GERMINARO, D. R. Disciplinas e professores de Astronomia nos cursos de licenciatura em Física das universidades brasileiras. Revista LatinoAmericana de Educação em Astronomia - RELEA, n. 18, p. 89-101, 2014.

ROMANZINI, J., BATISTA, I. L. Os Planetários como Ambientes Não-Formais para o Ensino de Ciências. VII ENPEC. Encontro Nacional de Pesquisa em Educação em Ciências. Florianópolis. nov. 2009.

SANTANA, A. R. Concepções dos professores sobre a utilização dos espaços não formais para o ensino de Astronomia. Dissertação de Mestrado. Universidade Estadual Paulista. Faculdade de Ciências, Bauru, 2017.

SIMSON, O. R. M.; PARK, M. B.; FERNANDES, R. S. Educação Não-Formal: cenários da criação. Campinas: Editora da UNICAMP, 2001. 